\title{
Surface pollen assemblages as indicators of human impact in the warm temperate hilly areas of eastern China
}

\author{
DING Wei, PANG RuiMing, XU QingHai*, LI YueCong \& CAO XianYong \\ College of Resources and Environmental Sciences and Hebei Key Laboratory of Environmental Change and Ecological Construction, Hebei \\ Normal University, Shijiazhuang 050016, China
}

Received October 11, 2010; accepted December 23, 2010

\begin{abstract}
Investigation of 78 surface pollen samples from warm temperate hilly areas of eastern China shows that pollen assemblages in areas of different land use are significantly different. Pollen concentrations in wastelands are higher than in plantations; these, in turn, are higher than in farmlands; implying that pollen concentration decreases with increasing human impact. Arboreal pollen dominated by Pinus and Quercus is common in all samples. Herbaceous pollen percentages are higher while shrub pollen, fern spores and fern allies are lower in farmlands than in wastelands. Crop pollen is only detectable in and near farmlands; its percentages and concentrations decrease in wastelands. Cereal and Cruciferae pollen percentages average $16.7 \%$ and $6.7 \%$ in farmland respectively, but Cereal reduces to less than $3 \%$ and Cruciferae to less than $0.5 \%$ in nearby wastelands. Principle coordinates analysis and clustering analysis indicate that pollen assemblages from farmlands are distinguishable from those under other vegetation types. Occurrence of Poaceae, Chenopodiaceae, Artemisia, and Compositae pollen and Selaginella sinensis spores are closely related to human activities, and their types and frequencies indicate intensity of human impact. The spatial distribution of crops, Chenopodiaceae, and Artemisia reflects changes in both natural environments and human activities. Percentages of cereal and Cruciferae pollen, for example, increase with decreasing altitude, but decrease with increasing latitude. Understanding pollen assemblages under artificial and human-disturbed vegetation in hilly areas may aid understanding of human impacts on the plains during the early-middle Holocene.
\end{abstract}

pollen assemblages, hilly areas, surface pollen, farmland, wasteland, human impact

Citation: Ding W, Pang R M, Xu Q H, et al. Surface pollen assemblages as indicators of human impact in the warm temperate hilly areas of eastern China. Chinese Sci Bull, 2011, 56: 996-1004, doi: 10.1007/s11434-011-4350-1

Pollen-based paleoclimatic reconstruction and paleovegetational simulation play an important role in global change research [1-3]. The relationships between modern pollen, vegetation and climate need to be clearly understood. Many studies have investigated relationships between modern pollen, vegetation and climate in East Asia, on the Tibetan Plateau and in northern China [4-11]. Usually these studies have focused on natural vegetation. However, human-influenced vegetation is also important in forecasting climate and environmental change, particularly as human impact becomes increasingly serious. Some recent pollen researchers have begun to investigate human impacts on vegetation.

*Corresponding author (email: xuqinghai@mail.hebtu.edu.cn)
Examples include Hjelle's research of pollen assemblages in human-disturbed meadows in western Norway [12], Court-Picon et al. [13,14] compared pollen assemblages in natural and human-disturbed vegetation in the French Alps, Buttler et al. [15] studied meadow pollen assemblages with different human impacts in the Pyrenees Mountains, and Liu et al. [16] researched the pollen assemblages of grasslands that have different coverage and degrees of deterioration in northeastern China. All of the above studies reveal that pollen assemblages differ with human impact, and some types directly indicate human activity. However, these studies were too small to reveal regional vegetation changes and relationships with human activities. Through dust analysis of a large area of eastern China, Deng et al. [17] 
found that pollen assemblages in the anthropic zone are dominated by herbs, and that pollen assemblages were not significantly correlated with present vegetation.

Pollen assemblages can be expected to differ as different ecosystems are disturbed by humans in different ways at different times. Pollen research can detect the signals of human activities and provide evidence of agricultural development in the fossil pollen record.

Little research has investigated pollen assemblages of introduced or human-disturbed vegetation. China is an important cradle of agriculture, and long-term large scale cultivation has made it difficult to find an ecosystem unaffected by humans. Some studies have indicated that introduced and human-disturbed vegetation has significant regional characteristics in China. Pinus massoniana and Dicranopteris, for example, have increased abundance where vegetation is disturbed and rice farming is the main land use in southern China [18,19]. Pinus tabulaeformis, Artemisia, members of the family Chenopodiaceae and Selaginella sinensis have increased in northern China where wheat and corn are the main crops [20,21].

A detailed study of surface soil pollen has been conducted in the Anyang area; this was aimed at recognizing modern pollen assemblages and their spatial distributions in an area that has had intense human activity over a long period [22]. We chose a larger hilly area in warm temperate, eastern China to study pollen assemblages under introduced and human-disturbed vegetation. In this area human activities are less intense than on the plains. The area includes farmlands, but some secondary forest and shrub-grasslands are still common. Thus the vegetation may be close to the paleovegetation that was on the plains during the early stages of agriculture (early-middle Holocene). Study of pollen assemblages in the hills should be helpful to identifing human impacts in the fossil pollen records. Our aim is to assess pollen assemblage characteristics from areas with different types and intensities of human impact by comparison with natural vegetation. We discuss the degree and range of vegetation change caused by human impact. Our research will supply the basic information to select representative pollen types that indicate human impact under different climatic conditions. We will establish a semiquantitative or quantitative understanding of the relationships between pollen, vegetation, and climate in human impact areas.

\section{Study area}

The study area was on the Loess Plateau and Qinba Mountains $109^{\circ} 37^{\prime}-113^{\circ} 40^{\prime} \mathrm{E}$ and $32^{\circ} 19^{\prime}-37^{\circ} 46^{\prime} \mathrm{N}$ and lies within the subtropical, continental, monsoon zone, that includes the central and southern parts of northern China, and the northern parts of central China. Mean annual temperature ranges from $8^{\circ} \mathrm{C}$ to $16^{\circ} \mathrm{C}$, and mean annual precipitation from 400 to $1000 \mathrm{~mm}$ [23]. Vegetation zones extend from warm temperate, deciduous-broadleaf forests, to subtropical, mixed evergreen and deciduous-broadleaf forests. Today, forests are only found on the upper parts of mountains; indicating serious human impact. Deciduous-broadleaf forests are dominated by Quercus ( $Q$. liaotungensis, $Q$. variabilis) accompanied by Pinus (P. tabulaeformis, $P$. armandii). Mixed evergreen and deciduous-broadleaf forests are dominated by Cyclobalanopsis glauca and deciduous Quercus species, usually accompanied by Pinus henryi and P. armandii [24]. Most lower hilly areas are covered by shrubs such as Ostryopsis davidiana, Hippophae rhamnoides and Vitex negundo. Farmlands are mostly in piedmont areas, valleys, and on gentle hillsides.

\section{Methods}

We collected 78 surface soil samples (45 farmlands, 19 wastelands, 14 orchards and planted woodlands) in July 2008, along the route from Lüliang, Shanxi Province, to Xiangfan, Hubei Province, and returned to Yangquan, Shanxi Province (Figure 1). To reduce sampling error, samples were collected from surface soil (0-1 cm deep), and 4-5 collections within $2 \mathrm{~m}$ were mixed together. Latitude, altitude, and main plant species were recorded for each site.

Surface soil samples were treated with hydrofluoric acid following the method described by Faegri and Viersen [25], and $10 \mathrm{~g}$ of dry sample were added to one tablet of Lycopodium (27637 grains) used as a tracer. Pollen grains were identified and counted using a BX-51 Olympus light microscope at $400 \times$ magnification. More than 400 pollen grains were counted for each sample.

On the basis of previous research, pollen grains of the Poaceae were sorted into 2 types by grain size, circular pore diameter, and ornamentation [17,22]. Pollen grains shorter than $35 \mu \mathrm{m}$ (long axis) with thinner walls were designated weed Poaceae. Pollen grains longer than $35 \mu \mathrm{m}$ with clear ornamentation, a clear circular pore and similar grain size were considered cereal Poaceae.

A pollen diagram was drawn using TILIA [26]. Principal coordinates analysis (PCoA) and cluster analysis (CA) were conducted using MVSP (manufactured by Kovach Computing Services). Spatial distribution maps of the main pollen taxa were drawn using ArcMap (manufactured by Environmental Systems Research Institute, Inc.), and analysis of variance (ANOVA) of pollen concentrations in different areas was conducted using Excel (manufactured by Microsoft Corporation).

\section{Surface pollen assemblages}

A total of 103 plant taxa were identified from pollen in 78 samples. Pollen from 29 trees was recorded, with the 


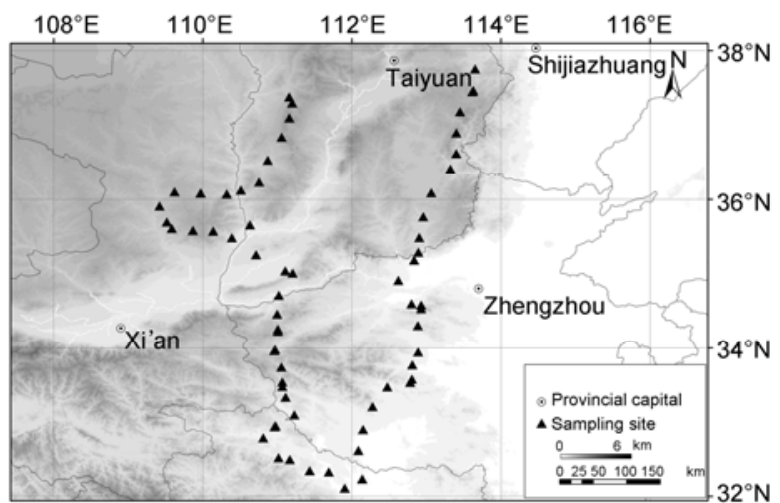

Figure 1 Locations of the 78 pollen sample sites.

average percentage of tree pollen per sample $37.8 \%$ and the maximum 67.6\%. Pinus, Quercus, Carpinus, Betula, Juglans, Populus, Ulmus were the major tree types and their pollen was found in nearly all samples. Anacardiaceae, $A i$ lanthus, Salix, Celtis, Castanea and Cupressaceae were also common but with lower percentages. Trees in the Lauraceae, and Castanopsis were only detected in the south of study area. 17 shrubs were identified (average 4.1\%, maximum 27.4\%); Elaeagnaceae, Ostryopsis, Rosaceae, Rhamnaceae, Syringa and Nitraria were the major types. The average percentage of herbaceous pollen (50 taxa) per sample was $46.5 \%$, and the maximum was $87.2 \%$. Common types were Poaceae, Artemisia, Chenopodiaceae, Polygonaceae, Compositae, Leguminosae, Cyperaceae, Typha,
Humulus, Urtica, Ranunculaceae, Amaranthaceae, Cruciferae, Labiatae, Liliaceae, Caryophyllaceae, Solanaceae and Convolvulaceae. Spores of ferns and fern allies (7 taxa) averaged $11.7 \%$, with a maximum of $92.3 \%$, and the dominant plant was Selaginella sinensis (Figure 2).

The samples were divided into 3 groups depending on land use. These were farmlands ( 23 corn fields, 4 rice fields, 18 mixed crop fields with corn, sorghum, peanut, soybean, potato, sweet potato, calabash, eggplant), wastelands (19 abandoned farmlands, barren hillsides and embankments) and plantations (5 Malus orchards, 4 planted Sophora woodlands, 1 Nicotiana tabacum field, 1 Zanthoxylum field, 1 Morus alba field, 1 citrus orchard, 1 vineyard). Pollen assemblages within a land use group were similar, but were obviously different between groups (Figure 3).

Pollen assemblages in farmlands were dominated by herbs. Pollen percentages of cereals and Cruciferae were higher here than in the other land use groups. Some crop pollens were only detected in farmlands and nearby areas. Linum usitatissimum pollen, for example, was detected in flax fields (1.4\%), Phaseolus pollen was detected in 2 bean fields (around 3\%), Malvaceae pollen was detected in farmlands where cotton is grown nearby (average 1.8\%, maximum $3.8 \%$ ), Pedaliaceae pollen was only detected in 4 farmlands where sesame is grown nearby (average 1.6\%, maximum $4.0 \%$ ).

Arboreal and herbaceous pollen percentages in wastelands were lower than in farmlands, especially for cereals, Cruciferae and Chenopodiaceae. However, Artemisia, Poaceae

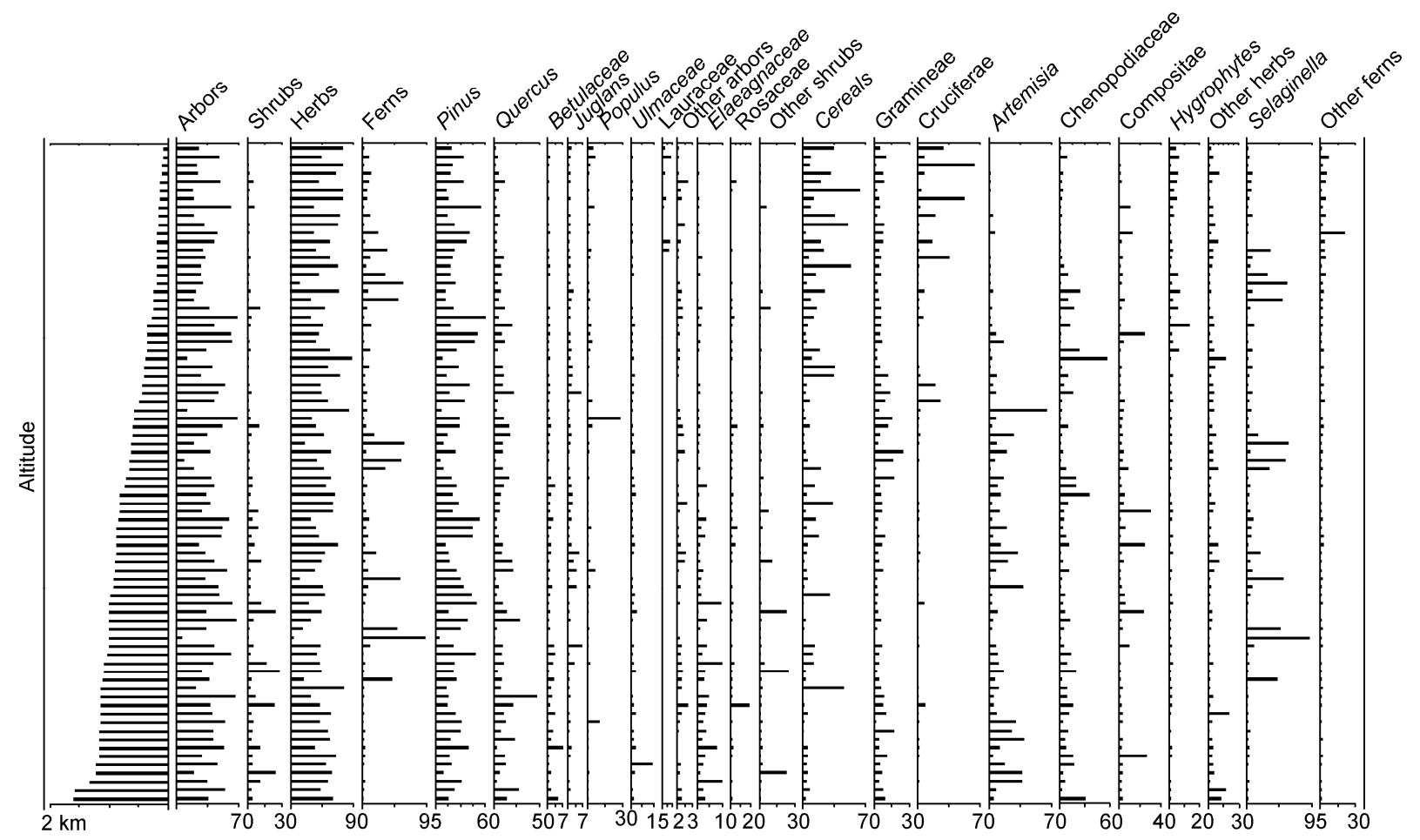

Figure 2 Percentages of major pollen taxa in surface soil. 


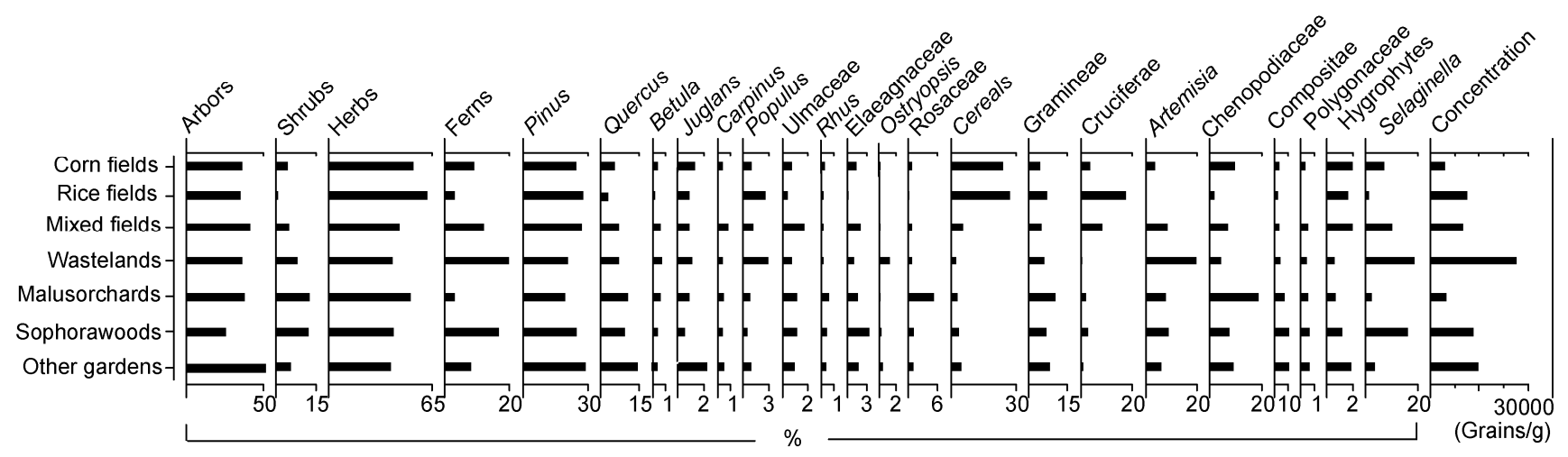

Figure 3 Comparison of major pollen types among different land uses.

weeds, Compositae (excluding Artemisia) and Polygonaceae pollen percentages were higher than in farmlands. Artemisia pollen was 5 times that in farmlands. Cereal pollen was not detected in 3 wasteland samples, and Cruciferae pollen was not found in 9 samples. Pollen from shrubs and fern spores were all higher than in farmlands.

In Malus orchards, Rosaceae pollen percentages (average $5.1 \%$ ) were higher than in the other land use groups. Arboreal and herbaceous pollen percentages in Malus orchards were similar to those in farmlands but higher than in wastelands. Among the herbaceous pollen types, Artemisia percentages were lower than in wastelands but higher than in farmlands. In contrast, percentages for cereals and Cruciferae were obviously higher than in wastelands but lower than in farmlands. Percentages for Chenopodiaceae, Poaceae, Compositae and Polygonaceae were all higher than in farmlands and wastelands. Fern spores were all lower than in farmlands or wastelands. Vitis pollen was only detected in the vineyard $(3.8 \%)$. The Solanaceae in the tobacco field, Rutaceae in the Citrus orchard and the Zanthoxylum field, and Leguminosae in the planted Sophora woodland were all less than $1 \%$. No Moraceae pollen was detected in the mulberry field.

To reduce the effect of sample distance and regional differences, 10 areas of farmland (cornfields and mixed fields with corn planting) were paired with 10 nearby wastelands no more than $20 \mathrm{~m}$ away. Differences of percentages and concentrations of main pollen types between farmlands and wastelands samples in these pairs were consistent with that in all 2 land use group samples. Average concentrations of main pollen types were lower in the farmland than in the wasteland except for cereals (Figure 4).

\section{Discussion}

\subsection{Differences in pollen concentration and human activity}

Average pollen concentration in the farmlands was 6943 grains/g and significantly lower than the 26333 grains/g in the wastelands. There are several possible reasons for this. First, tillage causes some surface pollen grains to spread to deeper soil layers. Second, the loose cultivated soil of the farmland allows some pollen to infiltrate deeper soil, particularly with irrigation or rainfall. Third, microbial diversity of the fertile farmland may cause degradation of pollen grains. In addition, continued weeding may cause some pollen grains to disappear, and fertilizer use may degrade pollen grains with poor preservation ability. Pollen concentrations in farmlands in our study are slightly lower than in farmlands (7227 grains/g) and wastelands (32704 grains/g) in the northwestern arid region [27], but slightly higher than in farmlands in central northern China (4227 grains/g) [28]. Further studies are needed to determine whether these are

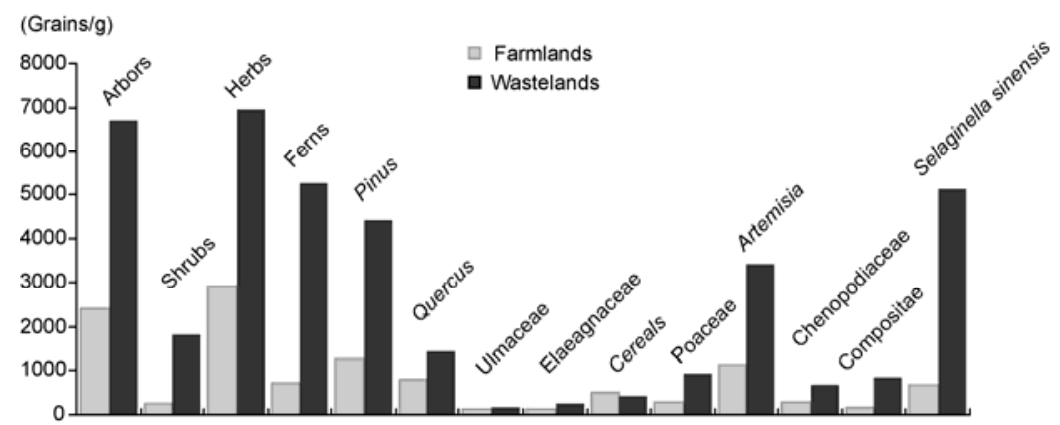

Figure 4 Average concentrations of main pollen types in the control group. 
regional differences.

Cornfields were found to have the lowest average pollen concentration (4057 grains/g), followed by Malus orchards (4606 grains/g), mixed fields (9699 grains/g), rice fields (11140 grains/g), Sophora woods (13095 grains/g), other plantations (14031 grains/g) and wastelands (26333 grains/ g). ANOVA $(\mathrm{F}>\mathrm{F}$ crit, $P$-value $\leqslant 0.01)$ indicates that these differences have statistical significance. Pollen concentrations in cornfields are lower than in mixed crop farmlands. Fruit trees are entomophilous plants with low pollen production [29,30], and crops are frequently planted between them, so that pollen concentrations in orchards are close to those in farmlands. Other plantations are often covered by weeds, and their pollen concentrations are higher than in farmlands and lower than in wastelands. Rice fields also have higher pollen concentrations. Generally, with an increase in human activities and decrease in biodiversity, pollen concentrations reduce (Figure 3). Our results support the existing conclusion that human impacts decrease pollen concentrations [31]. Whether these differences are large enough to enable distinction between different land use types needs further investigation.

\subsection{Differences in pollen assemblages with human impact}

Pollen assemblages are different in different land use types, and also differ with differing habitat or human impacts within the same land use type (Figures 2 and 3). To distinguish different land use by pollen assemblage, PCoA was conducted with the percentages of pollen types. The results suggest that the samples can be separated into two groups: (1) those from wasteland, orchards and woodland, and (2) those from farmlands (Figure 5). Farmland samples can be distinguished from those from other land use areas, but it is difficult to further distinguish farm type. Cultivation methods, such as interplanting and rotation, have a strong influ- ence, but most importantly crops such as corn, wheat, rice and millet belong to the Poaceae and their pollen is difficult to distinguish. The lower percentages of Rosaceae pollen in orchards and Leguminosae in planted Sophora woodlands make these pollen types difficult to use as land use indicators. In addition, the high percentages of similar weed pollens make it difficult to distinguish the wastelands from plantations by pollen assemblages.

To better understand how differences in pollen assemblage follow differing human impacts, CA was conducted for the main pollen types in farmlands and wastelands (Figure 6). The results show that Pinus, Quercus and other tree pollens have a similar ascendancy order in farmlands and wastelands and correspond to their relative abundance as regionally dominant trees. The ascendancy order of major herbaceous pollen types are cereals, Cruciferae, Selaginella sinensis, Chenopodiaceae, Artemisia and Poaceae in farmlands, and Selaginella sinensis, Artemisia, Poaceae, Chenopodiaceae, Compositae and cereals in wastelands. This indicates that the pollen presence of cereals, Poaceae, Chenopodiaceae, Artemisia and Selaginella sinensis is closely related to human activities in these hilly areas.

Our study area was mainly located in temperate deciduous forest and subtropical evergreen and deciduous-broadleaf mixed forest zones, where Pinus and Quercus are endemic. Pinus and Quercus pollen is widespread and abundant. Other forest trees such as Populus, Juglans, Betula, Carpinus and those in the Anacardiaceae are companion species. Their average pollen percentages are usually about $1 \%$; consistent with their actual distribution. The high percentages of Pinus pollen in farmlands and wastelands (25.8\% and $20.9 \%$ ) indicate that sampling sites should be far from pine forests [32]. Quercus pollen percentages are on average $7.4 \%$ in farmlands and $8.8 \%$ in wastelands; also indicating that the sampling sites should be distant from Quercus forests. In the Quercus forests Quercus pollen was $55 \%$ in the Taibai Mountains [33] and $18.7 \%$ in central

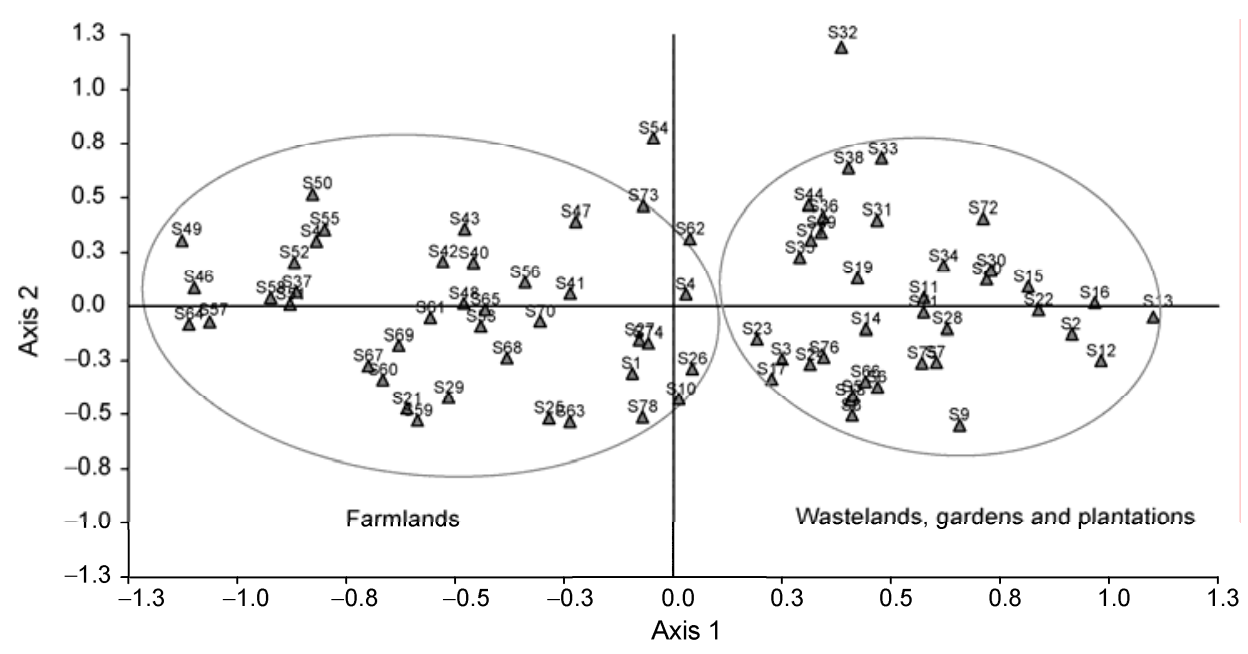

Figure 5 PCoA for 78 samples. 


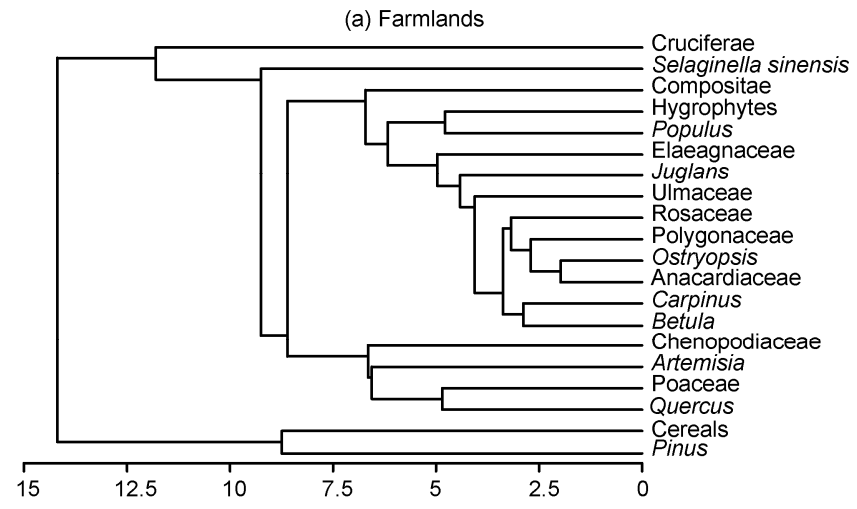

(b) Wastelands

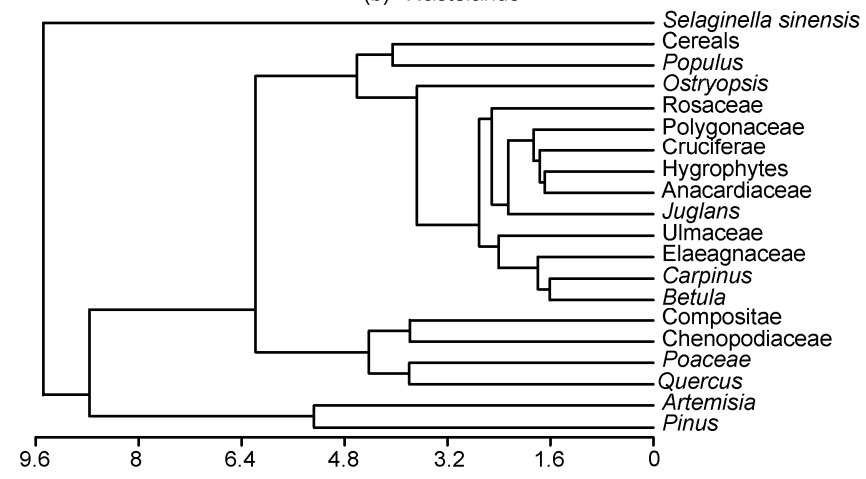

Figure 6 CA for main pollen types in farmlands (a) and wastelands (b).

northern China [28]. These results may suggest that farmlands in hilly areas are usually some distance from forests, hence, arboreal pollen percentages are similar between different land use types with an average of $37.8 \%$. And this is higher than the $18 \%$ in the Anyang region [22]. This further confirms that mountainous areas are important sources of arboreal pollen. Slightly higher arboreal pollen percentages in farmlands than in wastelands may be related to higher percentages of shrubs and ferns in wastelands, because these grow well in abandoned land [34]. However, some species of Elaeagnaceae are usually planted for medicine or food or as hedges; thus its percentage is higher in farmlands than in wastelands. Spores of ferns and fern allies are significantly more abundant in wastelands than in farmlands, because Selaginella sinensis usually grows in wastelands or under shrubs where ground soil has developed from limestone in northern China [20].

Herbaceous pollen is more abundant in farmlands than in wastelands, while Poaceae, Artemisia and Compositae are less abundant in farmlands than in wastelands. Higher Chenopodiaceae pollen percentages in farmlands probably result from vegetables planted in these sites (such as sugar beet and spinach). In general, although there are some slightly different pollen percentages in farmlands and wastelands, the pollen types are similar. Pollen assemblages in farmlands not only represent local vegetation components, but also reflect features of regional vegetation [28]. Cereal pollen percentages in farmlands are about $15 \%$ higher than in wastelands. In wastelands cereal pollen percentages sharply drop to below $3 \%$. One study showed that rice pollen percentages reduced about $20 \%$ even 5-10 m away from rice fields in a subtropical area of China [19]. To what extent crop pollen percentages decrease away from farmland will relate to crop types and cultivation methods.

Our average pollen percentages for the Poaceae (including cereals in this paragraph) and Artemisia in farmlands are lower than in central northern China [28], or the Anyang region [22,35]. Our pollen percentages for Poaceae, Artemisia and Chenopodiaceae in wastelands are also lower than in Anyang. This may relate to the lower human impact in hilly areas than on the plains. When our results are compared with paleosol samples in the Anyang region, the average herbaceous pollen percentages are similar; only our percentage of Poaceae is slightly higher (about 5\%), and our Artemisia and Chenopodiaceae percentages are slightly lower (about 4\%) than in the Anyang area. Excluding the effects of modern breeding and farming techniques, the pollen assemblages seem similar. This indicates that the pollen assemblages of hilly areas may be similar to those of plains during the early historical period when human activities were not so intense.

\subsection{Spatial distribution of major pollen taxa and human activities}

Figure 2 shows that percentages of major pollen types in 78 samples have a good correlation with altitude. Using ArcMap to map the spatial distribution of cereals, Cruciferae, Lauraceae, Quercus, Artemisia, Chenopodiaceae, shrubs and Selaginella sinensis, it is evident that distribution of these pollen types is also strongly influenced by latitude (Figure 7).

Shrubby pollen percentages increase with altitudes and northern latitudes. Quercus, Betulaceae, Ulmaceae and some other arboreal pollen increases slightly with altitudes, and Quercus percentages decrease from northwest to southeast. Lauraceae pollen appears in the southernmost areas at the lowest altitudes; thus indicating subtropical vegetation. Selaginella sinensis spores have the highest percentage abundance at about $34^{\circ} \mathrm{N}$ in the southern central part of our study area. Hygric pollen and other spores excluding Selaginella sinensis decrease with increasing altitudes. There were no significant relationships among Pinus, Poaceae or Compositae pollen and altitudes, presumably due to the over-representation of Pinus and many genera in the Poaceae and Compositae. Altitudinal and latitudinal changes obviously relate to changes in natural factors such as temperature and precipitation, and are in accordance with the natural distribution of these species. Pollen frequencies and percentages for Populus are higher at low altitudes than at high altitudes. Juglans pollen percentages are slightly higher between 500 and $1000 \mathrm{~m}$ elevation and probably relate to both the natural distribution and human planting. 
Pollen percentages for cereals and Cruciferae increase while those for Artemisia and Chenopodiaceae decrease with decreasing elevation and latitude, except for an ab- normal rise in Chenopodiaceae pollen around $200-500 \mathrm{~m}$ altitude (Table 1). These results suggest that human impacts become more serious with decreasing altitude.

Table 1 Percentages of several pollen taxa in farmlands and corresponding altitude

\begin{tabular}{ccccccc}
\hline Altitude & Crops & Cereals & Cruciferae & Artemisia & Chenopodiaceae & Sample number \\
\hline$<200$ & 40.7 & 25.0 & 15.5 & 1.0 & 2.5 & 15 \\
$200-500$ & 23.8 & 15.9 & 6.6 & 2.6 & 14.7 & 9 \\
$500-1000$ & 12.1 & 11.4 & 0.4 & 6.2 & 7.4 & 13 \\
$>1000$ & 11.2 & 10.9 & 0.2 & 13.8 & 8.6 & 8 \\
\hline
\end{tabular}
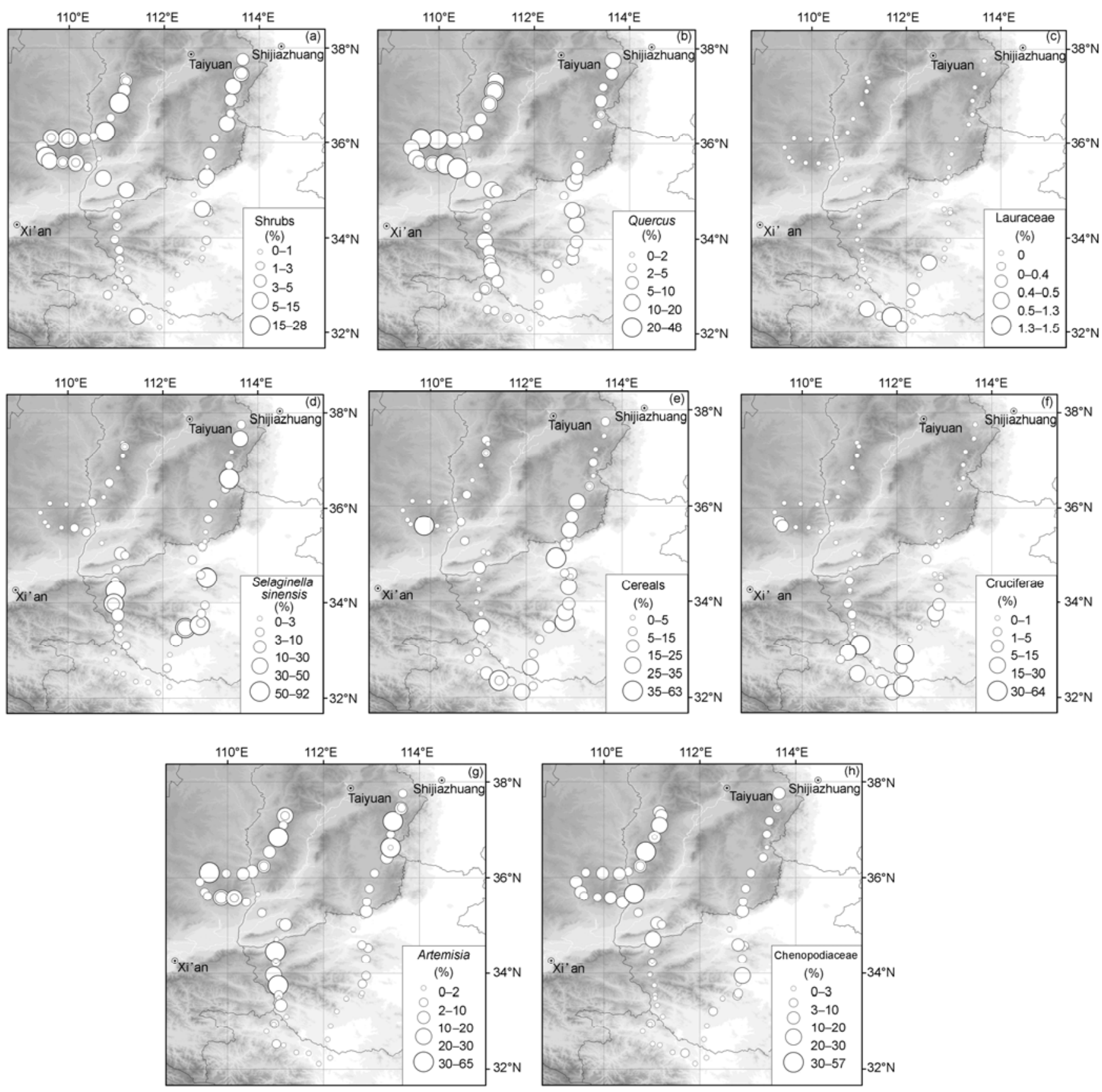

Figure 7 Spatial distribution of the main pollen types. 
Cereal percentages gradually increase with decreasing latitude (Figure 7(e)) and Cruciferae pollen percentages are much higher in the southern part of the study area (Figure $7(f)$ ), indicating that agricultural activities increase from the north to the south. The southeast is a mixed cropping area with rice, wheat and other crops [24], and is also one of the major areas where rapeseed is planted. Rotation between rice and rapeseed is common in this area. Surface pollen assemblages reflect this cropping pattern, suggesting that pollen assemblages can indicate not only agricultural production [31,36], but also cultivation method. Pollen percentages for Artemisia and Chenopodiaceae decrease from the arid Loess Plateau with its higher altitude, to the more humid southeast of central China (Figure $7(\mathrm{~g}),(\mathrm{h})$ ). These results thus support the conclusion of many previous studies, that Artemisia and Chenopodiaceae reflect both the human impact and aridification of the climate [37,38].

In summary, our research into the distribution of pollen types and their correlation with environmental or human factors on this scale will be beneficial to understand the relationship between pollen assemblages impacted by human activities, vegetation and climate.

\section{Conclusions}

(1) Crop pollen concentrations in farmlands are higher than in wastelands, but other main types are all higher in wastelands. Pollen concentrations are lower in simple vegetation types with serious human impacts than in other vegetation types; thus indicating that human impact causes pollen concentrations to decrease. PCoA indicates that the abundances of Poaceae, Chenopodiaceae, Artemisia and Selaginella sinensis are closely related to human activity; their percentages are different in farmlands from wastelands and thus reflect the intensity of human activity.

(2) Arboreal pollen types and percentages are similar between most samples, while herbaceous pollen types and percentages show the impact of human activities. Crop pollens and their percentages are indicators of the cultivation methods and scale of agriculture. Cereals and Cruciferae pollen percentages averaged $16.7 \%$ and $6.7 \%$ in farmland, respectively, but cereals decreased to less than $3 \%$ and Cruciferae to less than $0.5 \%$ in nearby wastelands. Based on pollen type, farmlands can be distinguished from other land uses. However, it is difficult to distinguish farm types, due to cultivation methods such as interplanting and rotation, and also identify pollen within the Poaceae family. The low pollen production of the dominant trees in orchards and Sophora woodlands also make it difficult to distinguish wastelands and plantations by their pollen assemblages.

(3) Percentages of most pollen types change with altitude and latitude. These differing distributions can reflect changes in both the natural environment and intensity of human impact. Knowledge of pollen assemblages in planted and human-disturbed hilly vegetation may help reconstruct paleovegetation in the plains as it was during the early agricultural period.

This work was supported by the Key Program of the National Natural Science Foundation of China (40730103), the National Natural Science Foundation of China (40672107 and 41071132) and Hebei Natural Science Foundation (D2008000186 and D2009000300).

1 Sun X J, Wang F Y, Song C Q. Pollen climate response surfaces of selected taxa from Northern China. Sci China Ser D-Earth Sci, 1996, 39: 486-492

2 Song C Q, Lü H Y, Sun X J. Boreal pollen climatic factor transfer function and its application in paleoclimate reconstruction. Chinese Sci Bull, 1997, 42: 2183-2186

3 Song $\mathrm{C}$ Q, Sun X J, Advances in studies of quaternary palynology in china (in Chinese). Adv Earth Sci, 1999, 14: 401-405

4 Zheng Z, Cour P, Zhou H P, et al. Modern pollen rain in Hainan Island, southern China: Altitudinal pollen distribution in the tropical rain forest (in Chinese). Acta Palaeontol Sin, 2002, 41: 487-496

5 Lü H Y, Wang S Y, Shen C M, et al. Spatial pattern of modern Abies and Picea pollen in the Qinghai-Xizang Plateau (in Chinese). Quat Sci, 2004, 24: 39-49

6 Xu Q H, Li Y C, Yang X L et al. Study on surface pollen of major steppe communities in Northern China (in Chinese). Geogr Res, 2005, 24: 394-402

7 Xu Q H, Li Y C, Yang X L et al. Surface pollen assemblages of some major forest types in northern china (in Chinese). Quat Sci, 2005, 47: 585-597

8 Xu Q H, Li Y C, Li Y, et al. Modern pollen process and several issues concerning the study of Quaternary environment (in Chinese). Prog Nat Sci, 2006, 16: 647-653

9 Li Y C, Xu Q H, Yang X L, et al. Pollen assemblages of major steppe communities in China (in Chinese). Acta Ecol Sin, 2005, 25: 555-564

$10 \mathrm{Li} \mathrm{Y} \mathrm{C,} \mathrm{Xu} \mathrm{Q} \mathrm{H,} \mathrm{Xiao} \mathrm{J} \mathrm{L,} \mathrm{et} \mathrm{al.} \mathrm{Indication} \mathrm{of} \mathrm{some} \mathrm{major} \mathrm{pollen} \mathrm{taxa}$ in surface samples to their parent plants of forest in Northern China (in Chinese). Quat Sci, 2005, 25: 598-608

11 Li Y C, Xu Q H, Xiao J L, et al. Relationship between surface pollen and vegetation in some shrub communities of northern China (in Chinese). Sci Geogr Sin, 2007, 27: 205-210

12 Hjelle L K. 1997. Relationships between pollen and plants in human-influenced vegetation types using presence-absence data in western Norway. Rev Palaeobot Palynol, 99: 1-16

13 Court-Picon M, Alexandre B, Beaulieu J L. Modern pollenvegetation relationships in the Champsaur valley (French Alps) and their potential in the interpretation of fossil pollen records of past cultural landscapes. Rev Palaeobot Palynol, 2005, 135: 13-39

14 Court-Picon M, Alexandre B, Beaulieu J L. Modern pollen/vegetation/land-use relationships in mountain environments: An example from the Champsaur valley (French Alps). Veget Hist Archaeobot, 2005, 15: 151-168

15 Buttler A, Mazier F, Galop D. Modern pollen assemblages from grazed vegetation in the western Pyrenees, France: A numerical tool for more precise reconstruction of past cultural landscapes. Holocene, 2006, 16: 91-103

16 Liu H Y, Wang Y, Tian Y H, et al. Climatic and anthropogenic control of surface pollen assemblages in East Asian steppes. Rev Palaeobot Palynol, 2006, 138: 281-289

17 Deng Y, Zheng Z, Cour P, et al. Relation between pollen ratios and climate in east and an attempt of paleoclimate reconstruction (in Chinese). Acta Palaeontol Sin, 2002, 41: 508-516

18 Qin X S, Liu Y Q, Xin F W. Species diversity in undergrowth of artificial forest on lower hilly land (in Chinese). J Trop Subtrop Bot, 2003, 11: 223-228

19 Yang S X, Zheng Z, Huang K Y, et al. Surface pollen analysis in subtropical double-cropping rice areas and its archaeological 
application (in Chinese). Quat Sci, 2010, 30: 262-272

20 Zhang J H, Kong Z C. Significance on ecological indication of Selaginella sinensis in reconstructing past environment (in Chinese). Acta Bot Boreal-Occident Sin, 1999, 19: 530-537

21 Du X J, Jiang F Q, Jiao Z H. Vegetation restoration in western Liaoning hilly region: A study based on succession theory and degradation degree of ecosystem (in Chinese). Chin J Appl Eco. 2004, 15: $1507-1511$

22 Wang X L, Li Y C, Xu Q H, et al. Pollen assemblages from different agricultural units and their spatial distribution in Anyang area. Chinese Sci Bull, 2010, 55: 544-554

23 Jiao B C. Atlas of Physical Geography in China (in Chinese). Beijing: SinoMaps Press, 1984. 59-60

24 Zhang X S. Vegetation Map of China and Its Geographic Pattern (in Chinese). Beijing: The Geological publishing House, 2007. 538-608

25 Faegri K, Viersen J. Textbook of Pollen Analysis (3rd). Oxford: Blackwell, 1989. 295

26 Grimm E C. TILIA and TILIA GRAPH PC spreadsheet and graphics software for pollen data. INQUA, Working Group on Data-Handling Methods. Newslett, 1990, 4: 5-7

27 Ma Y L, Xu Q H, Huang X Z, et al. Pollen assemblage characters of human disturbed vegetation in arid area in northwestern China (in Chinese). J Palaeogeogr, 2009, 11: 542-550

28 Zheng Z H, Tian F, Cao X Y, et al. A Study on surface pollen assemblage and relationship with vegetation from some vegetation types in central North China (in Chinese). Geogr Geo-Inf Sci, 2008, 4: 92-97

29 Wang F Y, Song C Q, Sun X J. Study on surface pollen in middle Inner
Mongolia, China (in Chinese). Acta Bot Sin, 1996, 38: 902-9091

30 San Y L, Ma Y Z, Gao S Y, et al. Pollen assemblages and numberical analysis of surface samples from Xinlongshan National Reserve, Gansu (in Chinese). Acta Palaeontol Sin, 2008, 47: 457-467

31 Yang X D, Shen J, Richard T J, et al. Pollen evidence of early human activities in the Erhai basin, Yunnan Province. Chinese Sci Bull, 2005, 50: 569-577

$32 \mathrm{Li} \mathrm{W} \mathrm{Y,} \mathrm{Yao} \mathrm{Z} \mathrm{J.} \mathrm{A} \mathrm{study} \mathrm{on} \mathrm{the} \mathrm{quantitative} \mathrm{relationship} \mathrm{between}$ Pinus pollen in surface sample and Pinus vegetation (in Chinese). Acta Bot Sin, 1990, 32: 943-950

33 Li Y C, Xu Q H, Cao X Y, et al. Pollen influx and surface pollen assemblage on the northern slope of Taibai Mountain (in Chinese). Geogr Res, 2008, 27: 536-546

34 Li Y Y, Zhou L P, Cui H T. Pollen indicators of human activity. Chinese Sci Bull, 2008, 53: 991-1002

35 Xu Q H, Cao X Y, Wang X L, et al. Generation of Yinxu culture: Environmental background and impacts of human activities (in Chinese). Quat Sci, 2010, 30: 273-286

36 Poska A, Saarse L, Veski S. Reflections of pre- and early-agrarian human impact in the pollen diagrams of Estonia. Palaeogeogr Palaeoclimatol Palaeoecol, 2004, 209: 37-50

37 Ren G Y. Influence of Human activities on the late holocene vegetation changes at Maili, northeast China (in Chinese). Sci Geogr Sin, 1999, 19: 42-48

38 Liu H Y, Li Y Y. Pollen indicators of climate change and human activities in the semiarid region (in Chinese). Acta Palaeontol Sin, 2009, 48: 211-221

Open Access This article is distributed under the terms of the Creative Commons Attribution License which permits any use, distribution, and reproduction in any medium, provided the original author(s) and source are credited. 